\title{
Usefulness of metabolic syndrome score in the prediction of angiographic coronary artery disease severity according to the presence of diabetes mellitus: relation with inflammatory markers and adipokines
}

Jong-Youn Kim ${ }^{1}$, Eui-Young Choi ${ }^{1}$, Hee-Sun Mun ${ }^{1}$, Pil-Ki Min ${ }^{1,2^{*}}$, Young-Won Yoon ${ }^{1,2}$, Byoung Kwon Lee ${ }^{1}$, Bum-Kee Hong ${ }^{1}$, Se-Joong Rim ${ }^{1}$ and Hyuck Moon Kwon ${ }^{1}$

\begin{abstract}
Background: It is a matter of debate whether metabolic syndrome (MS) improves cardiovascular risk prediction beyond the risk associated with its individual components. The present study examined the association of MS score with high sensitivity C-reactive protein (hs-CRP), interleukin-6 (IL-6), resistin, adiponectin, and angiographic coronary artery disease (CAD) severity according to the presence of DM. In addition, the predictive value of various clinical and biochemical parameters were analyzed, including the MS score for angiographic CAD.

Methods: The study enrolled 363 consecutive patients (196 men, $62 \pm 11$ years of age) who underwent coronary angiography for evaluation of chest pain. Blood samples were taken prior to elective coronary angiography. MS was defined by the National Cholesterol Education Program criteria, with MS score defined as the numbers of MS components. CAD was defined as > 50\% luminal diameter stenosis of at least one major epicardial coronary artery. CAD severity was assessed using the Gensini score.

Results: Of the 363 patients studied, 174 (48\%) had CAD and 178 (49\%) were diagnosed with MS. When the patients were divided into 4 subgroups according to MS score $(0-1,2,3,4-5)$, IL-6 levels and the CAD severity as assessed by the Gensini score increased as MS scores increased. In contrast, adiponectin levels decreased significantly as MS scores increased. When subjects were divided into two groups according to the presence of DM, the relationships between MS score and IL-6, adiponectin, and Gensini score were maintained only in patients without DM. Age, smoking, DM, MS score, and adiponectin independently predicted angiographic CAD in the whole population. However, age is the only predictor for angiographic CAD in patients with DM.

Conclusions: In the presence of DM, neither adipokines nor MS score predicted angiographic CAD. However, in non-diabetic patients, IL-6 and adiponectin showed progressive changes according to MS score, and MS score was an independent predictor of CAD in patients without DM.
\end{abstract}

Keywords: Metabolic syndrome, Adipokines, Coronary artery disease, Diabetes mellitus

\footnotetext{
* Correspondence: cardioblues@yuhs.ac

${ }^{1}$ Cardiology Division, Department of Internal Medicine, Gangnam Severance

Hospital, Yonsei University College of Medicine, 211 Eonju-ro, Gangnam-gu,

Seoul 135-720, Korea

${ }^{2}$ Severance Institute for Vascular and Metabolic Research, Yonsei University

College of Medicine, Seoul, Korea
} 


\section{Background}

Metabolic syndrome (MS) is considered a clinical predictor of cardiovascular disease [1-3], and patients with MS have a higher incidence of coronary artery disease (CAD) than individuals without MS [4,5]. Visceral adipose tissue plays a crucial role in the pathogenesis of MS [6]. Adipokines, which are bioactive derivatives produced by the adipose tissue, may contribute to the pathogenesis of cardiovascular disease in patients with MS. [7,8].

However, it is still debatable whether the CAD risk associated with MS is above and beyond the risk associated with its individual components [9,10]. Previous studies have reported that the number of markers of MS, or the MS score, is more useful than a binary definition of MS to predict severity of CAD [11,12]. Moreover, the predictability of MS for CAD arises primarily from high fasting blood glucose [12] and the relationship between the MS score and $\mathrm{CAD}$ severity is unclear in the presence of diabetes mellitus (DM) [13].

To the best of the author's knowledge, the effect of DM on the relationship between MS score and levels of inflammatory markers or adipokines has not been investigated. Therefore, the present study examined the association of MS score with high sensitivity C-reactive protein (hs-CRP), interleukin-6 (IL-6), resistin, adiponectin, and angiographic $\mathrm{CAD}$ severity according to the presence of DM. In addition, this study analyzed the predictive value of various clinical and biochemical parameters, including MS score, for angiographic CAD.

\section{Methods}

\section{Subjects}

The study prospectively enrolled 363 consecutive patients who underwent their first elective coronary angiography for evaluation of chest pain from October 2007 to June 2008 at the Gangnam Severance Hospital, Yonsei University College of Medicine, Seoul, Korea. Patients who had a history of previous percutaneous coronary intervention or coronary artery bypass graft were excluded. Other exclusion criteria were acute myocardial infarction, apparent infectious disease, chronic kidney disease, chronic inflammatory disorders, and malignancy.

The study protocol was approved by the Institutional Review Board of the Gangnam Severance Hospital, Yonsei University College of Medicine, and a written informed consent was obtained from each patient.

\section{Definition of metabolic syndrome}

The presence of MS was determined using the updated 2005 Third Adult Treatment Panel of the National Cholesterol Education Program criteria [14]. In the present analysis, central obesity was considered to be present if waist circumference was $\geq 90 \mathrm{~cm}$ in men and $\geq 80 \mathrm{~cm}$ in women, using thresholds for the Asian population. Those who had any three or more of the five components were classified as having MS. The MS score was defined as the number of constituents of MS.

\section{Biochemical assessment}

Blood samples were taken in the early morning after overnight fasting prior to elective coronary angiography. Serum lipid profiles, fasting blood glucose, serum insulin, and high sensitivity hs-CRP were measured in the hospital laboratory. Insulin resistance was evaluated in non-diabetic patients by the homeostatic model assessment as previously described [15].

Blood samples for analysis of IL-6, resistin, and adiponectin were collected through the vascular sheath prior to angiography. Serum was separated and stored frozen at $-80^{\circ} \mathrm{C}$ for subsequent assay. Serum resistin and IL-6 were measured by enzyme-linked immunosorbent assay using commercial kits (R\&D Systems, Minneapolis, MN, USA). Serum adiponectin levels were measured using a commercially available radioimmunoassay (Linco Research, St. Charles, MO, USA).

\section{Angiographic assessment}

Coronary angiography was performed by conventional methods via the femoral artery. The angiographic characteristics of all coronary lesions in the index coronary angiogram were obtained by carefully reviewing the angiogram. CAD was defined as $>50 \%$ luminal diameter stenosis of at least one major epicardial coronary artery. CAD severity was assessed using the Gensini scoring system as previously described [16]. Grades of luminal stenosis were determined by consensus opinion of two experienced interventional cardiologists.

\section{Statistical analyses}

Continuous data are expressed as the mean \pm S.D., and categorical data are presented as numbers and percentages. Differences in categorical variables were analyzed using the chi-square test, and continuous variables were analyzed using the Student's t-test. Comparisons among groups according to MS score were calculated with an analysis of variance for continuous variables. Multivariate logistic regression analysis was performed to determine predictors of angiographic CAD. The base- 2 logarithms $\left(\log _{2}\right)$ of the levels of hs-CRP, IL-6, resistin, and adiponectin were used in logistic regression analysis to account for skewed distribution $[17,18]$. Thus, odds ratios for these parameters reflect the change in odds for an increase of $1 \log _{2}$ (the equivalent of a doubling of the value) in the measure. A 2-tailed $p$ value $<0.05$ was considered statistically significant. All statistical analyses were performed with PASW statistics version 18.0 (SPSS, Inc., Chicago, IL, USA). 
Table 1 Relative frequency of components of metabolic syndrome and clinical characteristics according to metabolic syndrome score

\begin{tabular}{|c|c|c|c|c|c|}
\hline \multirow[t]{2}{*}{ Parameters } & \multicolumn{4}{|l|}{ MS scores } & \multirow[t]{2}{*}{ Total $(n=363)$} \\
\hline & $0,1(n=95)$ & $2(n=90)$ & $3(n=104)$ & $4,5(n=74)$ & \\
\hline High BP ${ }^{*}$ & $17(18 \%)$ & $57(63 \%)$ & 87 (84\%) & $68(92 \%)$ & $229(63 \%)$ \\
\hline $\mathrm{High} \mathrm{FBG}^{+}$ & $4(4 \%)$ & $19(21 \%)$ & $44(42 \%)$ & $50(67 \%)$ & $117(32 \%)$ \\
\hline Low HDL-C $\mathrm{C}^{\ddagger}$ & $17(18 \%)$ & $38(42 \%)$ & $70(67 \%)$ & $68(92 \%)$ & $193(53 \%)$ \\
\hline High $\mathrm{TG}^{\S}$ & $1(1 \%)$ & $13(14 \%)$ & $43(41 \%)$ & 60 (81\%) & $117(32 \%)$ \\
\hline Abdominal obesityll & $23(24 \%)$ & $53(59 \%)$ & $68(65 \%)$ & $68(92 \%)$ & $212(58 \%)$ \\
\hline Age (years) & $61 \pm 11$ & $63 \pm 11$ & $63 \pm 11$ & $61 \pm 10$ & $62 \pm 11$ \\
\hline Male & $53(56 \%)$ & $47(52 \%)$ & $57(55 \%)$ & $39(53 \%)$ & $196(54 \%)$ \\
\hline Smoking & $14(15 \%)$ & $14(16 \%)$ & $14(14 \%)$ & $8(11 \%)$ & $50(14 \%)$ \\
\hline
\end{tabular}

MS = metabolic syndrome; $\mathrm{BP}=$ blood pressure; $\mathrm{FBG}$ = fasting blood glucose; $\mathrm{HDL}-\mathrm{C}=$ high-density lipoprotein cholesterol; $\mathrm{TG}=$ triglyceride.

* 130/85 mmHg.

$+\geq 110 \mathrm{mg} / \mathrm{dL}$.

${ }^{\ddagger}$ For men $<40 \mathrm{mg} / \mathrm{dL}$; for women $<50 \mathrm{mg} / \mathrm{dL}$.

$\S_{\geq} \geq 150 \mathrm{mg} / \mathrm{dL}$.

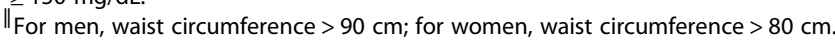

\section{Results}

A total of 363 patients (196 men, $62 \pm 11$ years of age) were enrolled in this study. Of these 363 patients, 174 (48\%) had CAD and 178 (49\%) were diagnosed with MS. The distribution of patients with an MS score of 0 to 5 is presented in Table 1. In most groups, high blood pressure was the most frequent abnormality, followed by increased waist circumference, low high-density lipoprotein cholesterol, high fasting blood glucose, and high triglycerides.

Demographic and biochemical characteristics of patients with and without MS are presented in Table 2. Compared to patients without MS, patients with MS had higher serum resistin levels $(7.1 \pm 7.0$ vs. $5.8 \pm 3.8 \mathrm{ng} / \mathrm{mL}, p=0.036)$ and lower serum adiponectin levels $(5.8 \pm 4.7$ vs. $7.5 \pm 5.7 \mu \mathrm{g} / \mathrm{mL}$, $p=0.002$ ). The levels of hs-CRP and IL- 6 were not significantly different between the groups with and without MS. The homeostasis model assessment of insulin resistance calculated for non-diabetic patients $(\mathrm{n}=276)$ was higher in patients with MS $(2.5 \pm 3.5$ vs. $1.4 \pm 1.7, p<0.001)$.

The prevalence of angiographic CAD and multivessel disease is higher in patients with MS (Table 3). Moreover, patients with MS had more severe CAD as assessed by the Gensini score $(20.7 \pm 27.7$ vs. $13.3 \pm 20.4, p=0.004)$. However, clinical presentation of CAD was not significantly different between the two groups.

When patients were divided into four subgroups according to MS score, IL-6 levels and CAD severity assessed by Gensini score tended to increase as MS score increased (Table 4). Serum resistin tended to increase with MS score, but this trend was not significant. In contrast, adiponectin levels significantly decreased as MS score increased. However, hs-CRP was not significantly different among the four subgroups.
Table 2 Clinical and biochemical characteristics according to the presence of metabolic syndrome

\begin{tabular}{|c|c|c|c|}
\hline Parameters & $\begin{array}{l}\text { Without MS } \\
(N=185)\end{array}$ & $\begin{array}{l}\text { With MS } \\
(N=178)\end{array}$ & $p$ value \\
\hline Age (years) & $61.8 \pm 11.5$ & $62.2 \pm 10.6$ & 0.728 \\
\hline Male & $100(54 \%)$ & $96(54 \%)$ & 0.981 \\
\hline BMI $\left(\mathrm{kg} / \mathrm{m}^{2}\right)$ & $23.7 \pm 2.8$ & $26.0 \pm 2.8$ & $<0.001$ \\
\hline Waist circumference (cm) & $85.9 \pm 8.6$ & $92.9 \pm 9.2$ & $<0.001$ \\
\hline Hip circumference $(\mathrm{cm})$ & $91.2 \pm 8.2$ & $95.2 \pm 7.0$ & $<0.001$ \\
\hline Waist-hip ratio & $0.94 \pm 0.07$ & $0.97 \pm 0.11$ & 0.064 \\
\hline Systolic BP (mmHg) & $122.9 \pm 17.4$ & $127.2 \pm 20.2$ & 0.028 \\
\hline Diastolic BP (mmHg) & $74.2 \pm 10.4$ & $75.7 \pm 12.0$ & 0.189 \\
\hline Smoking & $28(15 \%)$ & $22(12 \%)$ & 0.443 \\
\hline Hypertension & $74(40 \%)$ & $155(87 \%)$ & $<0.001$ \\
\hline Diabetes & $17(9 \%)$ & $70(39 \%)$ & $<0.001$ \\
\hline Total cholesterol (mg/dL) & $161.3 \pm 35.2$ & $153.3 \pm 41.8$ & 0.050 \\
\hline $\mathrm{TG}(\mathrm{mg} / \mathrm{dL})$ & $97.8 \pm 37.3$ & $158.5 \pm 78.2$ & $<0.001$ \\
\hline $\mathrm{HDL}-\mathrm{C}(\mathrm{mg} / \mathrm{dL})$ & $48.4 \pm 11.9$ & $39.6 \pm 8.5$ & $<0.001$ \\
\hline LDL-C (mg/dL) & $101.7 \pm 34.4$ & $97.6 \pm 30.9$ & 0.245 \\
\hline Lipoprotein(a) (mg/dL) & $22.4 \pm 28.5$ & $18.9 \pm 21.5$ & 0.196 \\
\hline $\mathrm{FBG}(\mathrm{mg} / \mathrm{dL})$ & $96.1 \pm 18.0$ & $106.6 \pm 25.6$ & $<0.001$ \\
\hline Serum insulin $(\mu \mathrm{lU} / \mathrm{mL})$ & $5.5 \pm 4.9$ & $9.4 \pm 13.3$ & $<0.001$ \\
\hline HOMA-IR & $1.4 \pm 1.7$ & $2.5 \pm 3.5$ & $<0.001$ \\
\hline hs-CRP (mg/L) & $5.4 \pm 13.7$ & $6.1 \pm 17.3$ & 0.716 \\
\hline $\mathrm{IL}-6(\mathrm{pg} / \mathrm{mL})$ & $2.3 \pm 3.7$ & $3.0 \pm 5.0$ & 0.103 \\
\hline Resistin (ng/mL) & $5.8 \pm 3.8$ & $7.1 \pm 7.0$ & 0.036 \\
\hline Adiponectin $(\mu \mathrm{g} / \mathrm{mL})$ & $7.5 \pm 5.7$ & $5.8 \pm 4.7$ & 0.002 \\
\hline
\end{tabular}

$\mathrm{MS}=$ metabolic syndrome; $\mathrm{BMI}=$ body mass index; $\mathrm{BP}=$ blood pressure; $\mathrm{TG}=$ triglyceride; $\mathrm{HDL}-\mathrm{C}=$ high-density lipoprotein cholesterol; $\mathrm{LDL}-\mathrm{C}=$ lowdensity lipoprotein cholesterol; FBG = fasting blood glucose; HOMA-IR = the homeostatic model assessment of insulin resistance; hs-CRP $=$ high sensitivity C-reactive protein; IL-6 = interleukin- 6 .

"HOMA-IR was calculated only for non-diabetic patients $(n=276)$. 
Table 3 Clinical presentation, angiographic diagnosis, and severity of coronary artery disease according to presence of metabolic syndrome

\begin{tabular}{llll}
\hline Parameters & $\begin{array}{l}\text { Without MS } \\
(\mathbf{N}=\mathbf{1 8 5})\end{array}$ & $\begin{array}{l}\text { With MS } \\
(\mathbf{N}=\mathbf{1 7 8})\end{array}$ & $\boldsymbol{p}$ value \\
\hline UA & $35(19 \%)$ & $46(26 \%)$ & 0.072 \\
Angiographic CAD & $76(41 \%)$ & $98(55 \%)$ & 0.008 \\
MVD & $36(20 \%)$ & $56(32 \%)$ & 0.009 \\
Gensini score & $13.3 \pm 20.4$ & $20.7 \pm 27.7$ & 0.004 \\
\hline
\end{tabular}

$\mathrm{MS}=$ metabolic syndrome; $\mathrm{UA}=$ unstable angina; $\mathrm{CAD}=$ coronary artery disease; MVD = multi-vessel disease.

When the subjects were divided into two groups according to the presence of DM, the relationships of IL-6, adiponectin, and Gensini score with MS score were maintained in patients without DM. In diabetic patients, however, there was no significant relationship between these parameters and MS score (Figure 1).

Various clinical and biochemical parameters including traditional CAD risk factors, inflammatory markers, adipokines, and MS score were analyzed for prediction of angiographic CAD. When a multivariate logistic regression analysis was performed, age, smoking, DM, MS score, and adiponectin independently predicted angiographic CAD in the entire population (Table 5). These analyses were then performed in subgroups according to presence of DM. Age, smoking, and MS score were still independent predictors for angiographic CAD in patients without DM. However, age is the only predictor for angiographic CAD in patients with DM (Table 6).

\section{Discussion}

MS is defined as the presence of any three or more of five quantitatively identified markers. Although the individual components of MS are related to one another, patients with MS could be comprised of heterogeneous subgroups [12]. Therefore, it has been a matter of debate whether MS improves cardiovascular risk prediction beyond the risk associated with its individual components $[9,10]$. Some studies have reported that MS score is more useful than the presence or absence of MS in predicting the severity of CAD [11,12]. Moreover, it has been suggested that MS predicts CAD based primarily on high fasting blood glucose [12], and the relationship between the MS score and CAD severity is unclear in the presence of DM [13].

The present study demonstrated that incremental changes in angiographic CAD severity assessed by the Gensini score were observed in accordance with MS score, and MS score was an independent predictor for angiographic CAD. However, in a diabetic subgroup, this association was not observed, and MS score could not predict CAD. These results are consistent with previous findings $[13,19]$. This study expands upon existing reports by demonstrating that MS scores are significantly related to IL-6 and adiponectin levels in the non-diabetic subgroup, but not in the diabetic subgroup. Regarding the prediction of angiographic $\mathrm{CAD}$, adiponectin showed marginal significance only in the non-diabetic subgroup [20].

Although the pathophysiological mechanism by which MS increases cardiovascular risk is still unclear [21], insulin resistance and central obesity seem to be essential components of MS [22,23]. Obesity as a predictor of cardiovascular events is related to many cardiovascular risk factors which are also components of MS [21,24]. It has been shown that visceral adipose tissue is an active endocrine organ which produces several bioactive derivatives including proinflammatory and prothrombotic adipokines, and protective adiponectin [25]. Visceral fat accumulation followed by increased production of proinflammatory adipokines and decreased production of adiponectin is associated with individual components of MS such as insulin resistance, hypertension, and dyslipidemia [6]. Eventually, these abnormalities could lead to atherosclerosis and cardiovascular events [26,27].

Some experts have suggested that increased cardiovascular risk associated with MS primarily arises from the

Table 4 Inflammatory markers, adipokines, and severity of angiographic coronary artery disease according to metabolic syndrome score

\begin{tabular}{|c|c|c|c|c|c|}
\hline \multirow[t]{2}{*}{ Parameters } & \multicolumn{4}{|l|}{ MS scores } & \multirow{2}{*}{$\begin{array}{l}p \\
\text { value }\end{array}$} \\
\hline & $0,1(n=95)$ & $2(n=90)$ & $3(n=104)$ & $4,5(n=74)$ & \\
\hline hs-CRP (mg/L) & $5.8 \pm 14.3$ & $5.0 \pm 13.1$ & $5.2 \pm 15.4$ & $7.3 \pm 19.8$ & 0.827 \\
\hline IL-6 (pg/mL) & $2.0 \pm 2.8$ & $2.6 \pm 4.4$ & $2.4 \pm 3.5$ & $4.0 \pm 6.5$ & 0.024 \\
\hline Resistin (ng/mL) & $5.7 \pm 4.1$ & $6.0 \pm 3.4$ & $6.6 \pm 5.0$ & $7.8 \pm 9.1$ & 0.077 \\
\hline Adiponectin $(\mu \mathrm{g} / \mathrm{mL})$ & $8.4 \pm 6.7$ & $6.6 \pm 4.2$ & $6.2 \pm 5.1$ & $5.3 \pm 4.2$ & 0.001 \\
\hline Gensini score & $9.4 \pm 16.8$ & $17.4 \pm 22.9$ & $18.9 \pm 24.8$ & $23.1 \pm 31.3$ & 0.002 \\
\hline
\end{tabular}

$\mathrm{MS}=$ metabolic syndrome; hs-CRP = high sensitivity C-reactive protein; IL-6 = interleukin-6. 

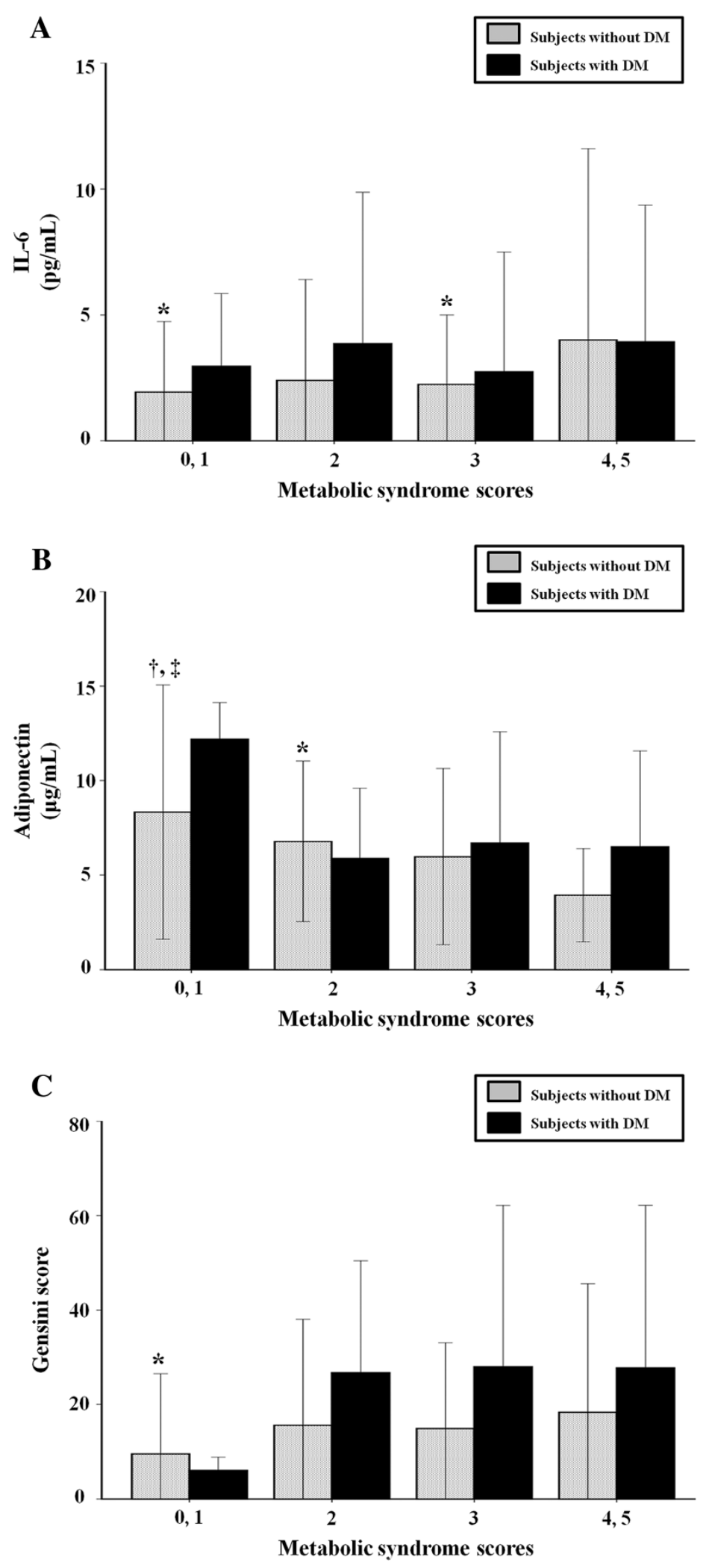

Figure 1 Relation of metabolic syndrome score with interleukin-6 (A), adiponectin (B), and Gensini score (C) according to the presence of diabetes. Data are expressed as mean \pm standard deviation. DM, diabetes mellitus; IL-6, interleukin- $6 .{ }^{*} p<0.05$ vs. metabolic syndrome (MS) scores 4, 5 group; $\uparrow p<0.05$ vs. MS score 3 group; $\neq p<0.001$ vs. MS score 4, 5 group. 
Table 5 Multiple clinical and biochemical parameters as determinants of angiographic coronary artery disease in multivariate logistic regression analysis

\begin{tabular}{lll}
\hline Parameters & Odds ratio $(\mathbf{9 5} \% \mathrm{Cl})$ & $\boldsymbol{p}$ value \\
\hline Age (per yr) & $1.046(1.018-1.074)$ & 0.001 \\
Smoking (yes) & $4.155(1.763-9.791)$ & 0.001 \\
Hypertension (yes) & $0.661(0.338-1.292)$ & 0.661 \\
Diabetes mellitus (yes) & $2.290(1.166-4.499)$ & 0.016 \\
Dyslipidemia (yes) & $1.507(0.746-3.045)$ & 0.253 \\
MS score (per 1 point) & $1.452(1.109-1.901)$ & 0.007 \\
hs-CRP (per doubling) & $1.052(0.862-1.284)$ & 0.619 \\
IL-6 (per doubling) & $1.064(0.781-1.450)$ & 0.695 \\
Resistin (per doubling) & $1.023(0.669-1.565)$ & 0.916 \\
Adiponectin (per doubling) & $0.683(0.469-0.995)$ & 0.047 \\
\hline
\end{tabular}

$\mathrm{MS}=$ metabolic syndrome; $\mathrm{hs}$ - $\mathrm{CRP}=$ high sensitivity $\mathrm{C}$-reactive protein $\mathrm{IL}-6=$ interleukin $-6 ; \mathrm{Cl}=$ confidence interval.

presence of DM, and DM should be excluded from the definition of MS [28]. The results of the present study also suggest that neither adipokines nor MS score have an incremental value for the prediction of $\mathrm{CAD}$ in the presence of DM. As DM is a very strong predictor of cardiovascular disease, the five components of MS and other non-traditional markers of cardiovascular disease did not improve cardiovascular disease prediction beyond the contribution of DM [29].

The definition of MS excludes other factors related to insulin resistance such as proinflammatory adipokines or adiponectin. It is unclear whether inclusion of these components would predict cardiovascular disease better than the current components [28,30,31]. However, in the non-diabetic subgroup, IL-6 and adiponectin changed gradually according to MS score, and MS score predicted angiographic CAD. Therefore, MS score could be used as a predictor of CAD in subjects without DM. The gradual change of inflammatory markers or adipokines according to MS score might be at least partly related with the usefulness of MS score in the prediction of CAD in nondiabetic patients.

The present study has several limitations. Firstly, the subjects in this study were patients who underwent coronary angiography for clinically suspected CAD. Therefore, the prevalence of DM $(24 \%)$ or CAD $(48 \%)$ was quite high, and selection bias may affect the results. Secondly, the severity of CAD was assessed by the Gensini scoring system based on the degree of angiographic luminal stenosis. Thus, lesion complexity or plaque vulnerability could not be analyzed in the present study. However, angiographic assessment of coronary stenosis is a widely accepted and clinically useful method for risk stratification in CAD patients. Lastly, this was a cross-sectional study and therefore it was not possible to determine causative relationships. In addition, the effects of medications that could influence the levels of inflammatory cytokines and adipokines, including anti-diabetic drugs, could not be fully analyzed in this study. Therefore, we cannot rule out completely the possibility that these medications might influence the results in some cases.

\section{Conclusions}

In the presence of DM, neither adipokines nor MS score had incremental value for predicting angiographic CAD. However, in non-diabetic patients, IL- 6 and adiponectin gradually changed according to the MS score, and MS score predicted angiographic CAD. Therefore, MS score could be a useful predictor of CAD in patients without DM.

Table 6 Multivariate regression analysis for the prediction of angiographic coronary artery disease in subgroups according to the presence of diabetes

\begin{tabular}{|c|c|c|c|c|}
\hline \multirow[b]{2}{*}{ Parameters } & \multicolumn{2}{|c|}{ Subjects without DM $(n=276)$} & \multicolumn{2}{|c|}{ Subjects with DM $(n=87)$} \\
\hline & Odds ratio $(95 \% \mathrm{Cl})$ & $p$ value & Odds ratio $(95 \% \mathrm{Cl})$ & $p$ value \\
\hline Age (per yr) & $1.043(1.012-1.075)$ & 0.006 & $1.079(1.003-1.161)$ & 0.041 \\
\hline Smoking (yes) & $3.843(1.514-9.753)$ & 0.005 & $9.428(0.803-110.639)$ & 0.074 \\
\hline Hypertension (yes) & $0.659(0.311-1.397)$ & 0.277 & $0.442(0.079-2.464)$ & 0.352 \\
\hline Dyslipidemia (yes) & $1.210(0.547-2.680)$ & 0.638 & $5.860(0.625-54.969)$ & 0.122 \\
\hline MS score (per 1 point) & $1.461(1.078-1.981)$ & 0.015 & $1.598(0.788-3.238)$ & 0.193 \\
\hline hs-CRP (per doubling) & $1.066(0.852-1.333)$ & 0.577 & $0.929(0.578-1.492)$ & 0.759 \\
\hline IL-6 (per doubling) & $1.087(0.760-1.555)$ & 0.648 & $1.063(0.557-2.030)$ & 0.853 \\
\hline Resistin (per doubling) & $0.990(0.610-1.609)$ & 0.969 & $1.195(0.469-3.043)$ & 0.709 \\
\hline Adiponectin (per doubling) & $0.646(0.417-1.001)$ & 0.051 & $0.985(0.424-2.290)$ & 0.972 \\
\hline
\end{tabular}

$\mathrm{MS}=$ metabolic syndrome; hs-CRP = high sensitivity C-reactive protein; IL-6 = interleukin-6; $\mathrm{DM}=$ diabetes mellitus; $\mathrm{Cl}=$ confidence interval. 


\section{Abbreviations}

MS: Metabolic syndrome; CAD: Coronary artery disease; DM: Diabetes mellitus; hs-CRP: High sensitivity C-reactive protein; IL-6: Interleukin-6; $\log _{2}$ : Base-2 logarithms.

\section{Competing interests}

The authors declare that they have no competing interests.

\section{Authors' contributions}

KJY, MPK, RSJ, and KHM participated in the design, coordination, and interpretation of this study. CEY and MHS contributed to the collection of clinical and laboratory data. YYW, LBK, and HBK contributed to the collection and analysis of angiographic data. KJY and MPK wrote this manuscript. All authors read and approved the final manuscript.

\section{Acknowledgements}

This research was supported by the Yonsei University College of Medicine, Internal Medicine Research Grant 2007-0219.

Received: 12 July 2013 Accepted: 25 September 2013 Published: 2 October 2013

\section{References}

1. Ford ES: Risks for all-cause mortality, cardiovascular disease, and diabetes associated with the metabolic syndrome: a summary of the evidence. Diabetes Care 2005, 28(7):1769-1778.

2. Galassi A, Reynolds K, He J: Metabolic syndrome and risk of cardiovascular disease: a meta-analysis. American J Med 2006, 119(10):812-819.

3. Gami AS, Witt BJ, Howard DE, Erwin PJ, Gami LA, Somers VK, Montori VM: Metabolic syndrome and risk of incident cardiovascular events and death: a systematic review and meta-analysis of longitudinal studies. J Am Coll Cardiol 2007, 49(4):403-414.

4. Isomaa B, Almgren P, Tuomi T, Forsen B, Lahti K, Nissen M, Taskinen MR, Groop L: Cardiovascular morbidity and mortality associated with the metabolic syndrome. Diabetes Care 2001, 24(4):683-689.

5. Solymoss BC, Bourassa MG, Lesperance J, Levesque S, Marcil M, Varga S, Campeau L: Incidence and clinical characteristics of the metabolic syndrome in patients with coronary artery disease. Coron Artery Dis 2003, 14(3):207-212.

6. Espinola-Klein C, Gori T, Blankenberg S, Munzel T: Inflammatory markers and cardiovascular risk in the metabolic syndrome. Front Biosci 2011, 16:1663-1674.

7. Nikolopoulou A, Kadoglou NP: Obesity and metabolic syndrome as related to cardiovascular disease. Expert Rev Cardiovasc Ther 2012, 10(7):933-939

8. Shah A, Mehta N, Reilly MP: Adipose inflammation, insulin resistance, and cardiovascular disease. JPEN J Parenter Enteral Nutr 2008, 32(6):638-644.

9. Iribarren C: The metabolic syndrome is no better than its components Minerva Cardioangiol 2007, 55(4):487-489.

10. Wang J, Ruotsalainen S, Moilanen L, Lepisto P, Laakso M, Kuusisto J: The metabolic syndrome predicts cardiovascular mortality: a 13-year followup study in elderly non-diabetic Finns. Eur Heart J 2007, 28(7):857-864

11. Solymoss BC, Bourassa MG, Campeau L, Sniderman A, Marcil M, Lesperance J, Levesque S, Varga S: Effect of increasing metabolic syndrome score on atherosclerotic risk profile and coronary artery disease angiographic severity. American J Cardiol 2004, 93(2):159-164.

12. Kim JY, Mun HS, Lee BK, Yoon SB, Choi EY, Min PK, Yoon YW, Hong BK, Rim SJ, Kwon HM: Impact of metabolic syndrome and its individual components on the presence and severity of angiographic coronary artery disease. Yonsei Med J 2010, 51(5):676-682.

13. Yoon SE, Ahn SG, Kim JY, Park JS, Shin JH, Tahk SJ, Lee SK, Kim TJ, Han N: Differential relationship between metabolic syndrome score and severity of coronary atherosclerosis as assessed by angiography in a non-diabetic and diabetic Korean population. J Korean Med Sci 2011, 26(7):900-905.

14. Grundy SM, Cleeman JI, Daniels SR, Donato KA, Eckel RH, Franklin BA, Gordon DJ, Krauss RM, Savage PJ, Smith SC Jr, et al: Diagnosis and management of the metabolic syndrome: an American Heart Association/National Heart, Lung, and Blood Institute Scientific Statement. Circulation 2005, 112(17):2735-2752.

15. Matthews DR, Hosker JP, Rudenski AS, Naylor BA, Treacher DF, Turner RC: Homeostasis model assessment: insulin resistance and beta-cell function from fasting plasma glucose and insulin concentrations in man Diabetologia 1985, 28(7):412-419.

16. Gensini GG: A more meaningful scoring system for determining the severity of coronary heart disease. American J Cardiol 1983, 51(3):606.

17. Otsuka F, Sugiyama S, Kojima S, Maruyoshi H, Funahashi T, Matsui K, Sakamoto T, Yoshimura M, Kimura K, Umemura S, et al: Plasma adiponectin levels are associated with coronary lesion complexity in men with coronary artery disease. J Am Coll Cardiol 2006, 48(6):1155-1162.

18. Tsimikas S, Brilakis ES, Miller ER, McConnell JP, Lennon RJ, Kornman KS, Witztum $J$, Berger PB: Oxidized phospholipids, Lp(a) lipoprotein, and coronary artery disease. New England J Med 2005, 353(1):46-57.

19. Sukhija R, Fahdi I, Garza L, Fink L, Scott M, Aude W, Pacheco R, Bursac Z, Grant A, Mehta JL: Inflammatory markers, angiographic severity of coronary artery disease, and patient outcome. American J Cardiol 2007, 99(7):879-884.

20. Baldasseroni S, Antenore A, Di Serio C, Orso F, Lonetto G, Bartoli N, Foschini A Marella A, Pratesi A, Scarantino S, et al: Adiponectin, diabetes and ischemic heart failure: a challenging relationship. Cardiovasc Diabetology 2012, 11:151.

21. Alberti KG, Eckel RH, Grundy SM, Zimmet PZ, Cleeman JI, Donato KA, Fruchart JC, James WP, Loria CM, Smith SC Jr: Harmonizing the metabolic syndrome: a joint interim statement of the International Diabetes Federation Task Force on Epidemiology and Prevention; National Heart, Lung, and Blood Institute; American Heart Association; World Heart Federation; International Atherosclerosis Society; and International Association for the Study of Obesity. Circulation 2009, 120(16):1640-1645.

22. Mottillo S, Filion KB, Genest J, Joseph L, Pilote L, Poirier P, Rinfret S, Schiffrin EL, Eisenberg MJ: The metabolic syndrome and cardiovascular risk a systematic review and meta-analysis. J Am Coll Cardiol 2010, 56(14):1113-1132.

23. Mouquet $F$, Cuilleret $F$, Susen $S$, Sautiere $K$, Marboeuf $P$, Ennezat PV McFadden E, Pigny P, Richard F, Hennache B, et al: Metabolic syndrome and collateral vessel formation in patients with documented occluded coronary arteries: association with hyperglycaemia, insulin-resistance, adiponectin and plasminogen activator inhibitor-1. Eur Heart J 2009, 30(7):840-849.

24. Yusuf S, Hawken S, Ounpuu S, Bautista L, Franzosi MG, Commerford P, Lang CC, Rumboldt Z, Onen CL, Lisheng $\mathrm{L}$, et al: Obesity and the risk of myocardial infarction in 27,000 participants from 52 countries: a case-control study. Lancet 2005, 366(9497):1640-1649.

25. Hutley L, Prins JB: Fat as an endocrine organ: relationship to the metabolic syndrome. Am J Med Sci 2005, 330(6):280-289.

26. Kim HM, Kim KJ, Lee HJ, Yu HT, Moon JH, Kang ES, Cha BS, Lee HC, Lee BW, Kim YJ: Epicardial adipose tissue thickness is an indicator for coronary artery stenosis in asymptomatic type 2 diabetic patients: its assessment by cardiac magnetic resonance. Cardiovasc Diabetology 2012, 11:83.

27. Siitonen N, Pulkkinen L, Lindstrom J, Kolehmainen M, Schwab U, Eriksson JG, Ilanne-Parikka P, Keinanen-Kiukaanniemi S, Tuomilehto J, Uusitupa M: Association of ADIPOR2 gene variants with cardiovascular disease and type 2 diabetes risk in individuals with impaired glucose tolerance: the Finnish Diabetes Prevention Study. Cardiovasc Diabetology 2011, 10:83.

28. Kahn R, Buse J, Ferrannini E, Stern M: The metabolic syndrome: time for a critical appraisal: joint statement from the American Diabetes Association and the European Association for the Study of Diabetes. Diabetes Care 2005, 28(9):2289-2304.

29. Liang KW, Lee WJ, Lee WL, Chen YT, Ting CT, Sheu WH: Diabetes exacerbates angiographic coronary lesion progression in subjects with metabolic syndrome independent of CRP levels. Clinica Chimica Acta; Int J Clin Chem 2008, 388(1-2):41-45.

30. Martin-Cordero L, Garcia JJ, Hinchado MD, Ortega E: The interleukin-6 and noradrenaline mediated inflammation-stress feedback mechanism is dysregulated in metabolic syndrome: effect of exercise. Cardiovasc Diabetology 2011, 10:42.

31. Antoniades C, Tousoulis D, Marinou K, Papageorgiou N, Bosinakou E, Tsioufis C, Stefanadi E, Latsios G, Tentolouris C, Siasos G, et al: Effects of insulin dependence on inflammatory process, thrombotic mechanisms and endothelial function, in patients with type 2 diabetes mellitus and coronary atherosclerosis. Clin Cardiol 2007, 30(6):295-300.

doi:10.1186/1475-2840-12-140

Cite this article as: Kim et al:: Usefulness of metabolic syndrome score in the prediction of angiographic coronary artery disease severity according to the presence of diabetes mellitus: relation with inflammatory markers and adipokines. Cardiovascular Diabetology 2013 12:140. 